\title{
BMJ Open Support to informal caregivers of patients with severe chronic obstructive pulmonary disease: a qualitative study of caregivers' and professionals' experiences in Swedish hospitals
}

\author{
Susann Strang, ${ }^{1,2}$ Josefin Fährn, ${ }^{1,2}$ Peter Strang, ${ }^{3}$ Agneta Ronstad, ${ }^{1}$ \\ Louise Danielsson ${ }^{1,4}$
}

To cite: Strang S, Fährn J, Strang P, et al. Support to informal caregivers of patients with severe chronic obstructive pulmonary disease: a qualitative study of caregivers' and professionals' experiences in Swedish hospitals. BMJ Open 2019;9:e028720. doi:10.1136/ bmjopen-2018-028720

\section{- Prepublication history for} this paper is available online. To view these files, please visit the journal online (http://dx.doi. org/10.1136/bmjopen-2018028720).

Received 27 December 2018

Revised 28 June 2019

Accepted 11 July 2019

Check for updates

(c) Author(s) (or their employer(s)) 2019. Re-use permitted under CC BY-NC. No commercial re-use. See rights and permissions. Published by BMJ.

${ }^{1}$ Research and development department, Angered Hospital Angered, Sweden

${ }^{2}$ Sahlgrenska Academy, University of Gothenburg Institute of Health and Care Sciences, Goteborg, Sweden ${ }^{3}$ Stockholms Sjukhems FoUU, Karolinska Institutet, Stockholm, Sweden

${ }^{4}$ Health and Rehabilitation, University of Gothenburg Institute of Neuroscience and Physiology, Goteborg, Sweden

Correspondence to

Dr Susann Strang;

susann.strang@gu.se

\section{ABSTRACT}

Objectives Informal caregivers of patients with chronic obstructive pulmonary disease (COPD) experience a heavy caregiver burden, but few studies have explored what support they need. The aim of this study was to describe perceptions of healthcare support to informal caregivers, both from the family caregiver's and the staff's perspective.

Design A qualitative interview study involving semistructured interviews and analysed with content analysis. Participants In total, 54 participated: 36 informal caregivers of patients with severe (stage 3-4) COPD and 17 healthcare staff.

Results Two main themes emerged from the analysis: (1) Ambiguity impedes provision of support. Both caregivers and staff experienced ambiguity. The informal caregivers needed emotional, practical and informational support but talked about unclear expectations, while the staff described an uncertainty about their duties regarding the families. There were no routines to unburden the families. Moreover, language and cultural barriers hampered their efforts. (2) Knowledgeable and perceptive communication is key to support. Both caregivers and staff described positive experiences of dialogue. The dialogue may facilitate means to caregiver support and was a support in itself.

Conclusions Our findings suggest that strategies and routines for caregiver support, including communication skills among the staff, should be developed, to move toward the family perspective advocated in palliative- and nursing family care.

\section{INTRODUCTION}

Chronic obstructive pulmonary disease (COPD) is a life changing disease associated with heavy symptom burden. ${ }^{12}$ As well as affecting the COPD patient, it also has a vast impact on families who live with and care for COPD patients. ${ }^{3}$ For example, Mi et al found that high patient fatigue was significantly associated with anxiety and depression in informal caregivers. ${ }^{4}$
Strengths and limitations of this study

- The sampling strategy with a large enough and varied sample allowed a comparison of both caregivers' and professionals' experiences.

- Collecting information through two methods was a way to capture sensitive, personal matters (interviews), as well as group dynamics (focus groups).

- Involving four different interviewers with different backgrounds reduced the risk for interviewer bias.

- A possible limitation is the difficulty to transfer the results beyond the context of Swedish hospitals.

Previous studies have confirmed that informal caregivers face a complex situation characterised by stress, worries and powerlessness. They experience increasing physical and emotional burden, and can feel forced into a restricted life, because they have to be constantly attentive ${ }^{5-9}$ Caring for people with advanced COPD, report higher subjective burden, negative impact on relational dynamics and identity, increasing illness, more depression, than those caring for relatives with early COPD. ${ }^{6}$ Caregiver depression, a sense of lack of future, uncertainty and anxiety are also found in other severe conditions. ${ }^{10} 11$

Palliative care has had a long tradition of involving the patients' families in the care, although to date, the research focus has been largely on cancer patients and their families. In all palliative care settings, including severe COPD, the family can be seen as a 'unit of care'-a cornerstone of palliative care, according to the current WHO definition. ${ }^{12}$ The spouse and/or other close relatives can be profoundly affected by living with a family member with COPD. However, in contrast to cancer, patients with advanced COPD are not 
always regarded as a self-evident target group for palliative care. This means that family support is not always regarded as an obvious part of the general care. ${ }^{1}$ There are also practical hindrances as support with activities of daily living is provided by the Swedish municipalities, whereas healthcare is a responsibility of the county councils. According to the National Board of Health and Welfare, the cooperation and coordination between municipalities and county councils is suboptimal and, moreover, they have even separate law regulations.$^{13}$

In order to improve quality of care and families' satisfaction with the healthcare service, ${ }^{14}$ it is important that they know what kind of help and support to expect from healthcare.

Today, there is a gap in knowledge between the informal caregivers' awareness about available support, and the actual support offered. It is also unclear whether informal caregivers and healthcare staff have similar views on caregiving support. ${ }^{1516}$

In this study, our understanding of 'caregiving support' means both to provide emotional, practical and educational support to the caregivers to help them in their current situation of caring for a chronically ill relative, and when needed, to refer to suitable healthcare interventions.

\section{AIMS}

Therefore, the aim of this study was to describe perceptions of caregiving support from healthcare to informal caregivers of patients with COPD from two perspectives: (1) the family caregiver's perspective and (2) the perspective of healthcare staff.

\section{MATERIAL AND METHODS}

A qualitative interview study with semi-structured, openended interview questions was performed to gain deeper insight into the phenomenon of support given to informal caregivers of patients with COPD and how the informal caregivers and healthcare professionals perceived the support. Interviews were conducted with both informal caregivers and healthcare staff working with patients with COPD. The methodology was qualitative content analysis, which offers flexibility to analysing different types of data and different depth of interpretation. ${ }^{17}$ In the research group were two highly experienced researchers (SS and PS) in conducting qualitative research with more than 20 years of experience in the field, two nurses (JF and AR) who provided a clinical perspective and another researcher experienced in qualitative research, but with a different background (mental health rehabilitation). The variation of experience and pre-understanding was viewed important to enrich the analytic discussions and to challenge interpretations by different perspectives. The Standards for Reporting Qualitative Research guidelines were used. ${ }^{18}$
The study started with five focus group (FG) sessions with the informal caregivers. FG interviews were chosen in order to elicit a multiplicity of views, interactions and emotional processes among the informal caregivers and obtain a range of experiences.$^{19}$ However, it appeared that the discussions in the FGs became partly superficial although two of the least information-rich groups were re-interviewed to gain deeper insights and encourage deeper reflection. Still, some participants felt uncomfortable to talk freely in a group about difficulties in caring for their loved ones. Therefore, individual interviews (II) were performed as well. In these interviews, the participants shared their emotions and thoughts more openly.

\section{PATIENT AND PUBLIC INVOLVEMENT}

Patients and public were not involved in the development and design of the study. Instead, the research questions and design were based on clinical experience and on a literature review.

\section{PARTICIPANTS}

Individuals (spouses, cohabitants or grown-up children living elsewhere) with personal experience of caring for a person with COPD (GOLD stage III-IV) were recruited during October 2016-February 2018 in a multicultural catchment area in southwest of Sweden. Three hospitals were involved in the study. They had specialised pulmonary clinics for patients with COPD, focusing on out-patient, team-based, mainly non-palliative care. Staff from the clinics contacted eligible participants and handed them information about the study in either Swedish or, if not fluent in Swedish, their native language. Purposive maximum variation sampling was aimed at with regard to participant gender and age country of birth, and language. ${ }^{20}$ In total, 36 informal caregivers and 17 healthcare staff were recruited (for details, please see the Results section).

The interviews were performed at the hospitals except for three interviews that were conducted by telephone. A senior researcher (SS) performed some of the interviews and trained the less experienced co-workers. During the interviews, the interviewer used follow-up questions. She mirrored back her impression of what the participant had described, so that the participant could confirm, disconfirm or elaborate on the subject. This questioning of meaning and continual checking of the information obtained, was a way to validate the findings in dialogue with the participants. ${ }^{21}$ The duration of the interviews was $20-70 \mathrm{~min}$ and the interviews consisted of semi-structured questions, with a possibility to follow-up questions (mainly open-ended or, in a few cases, close-ended questions). Interviews were audio-recorded and transcribed verbatim.

The number of participants was not pre-defined but determined based on 'saturation', that is, a sense of closure that occurs when data collection ceases to provide 
substantial new information and when thematic patterns in the data become evident. ${ }^{22}$ During the interviews, saturation was achieved after 30 caregiver interviews and 15 staff interviews. To accomplish maximum variation, interviews were carried on with further informants to ensure that no new aspects emerged which was not the case.

\section{Data analysis}

The interviews were analysed with qualitative content analysis focusing on similarities and differences between parts of the texts and on the manifest and latent content. ${ }^{23}$ The analysis process followed the steps described by Graneheim and Lundman.${ }^{17}$ Data from both individual and FG interviews were used, as they provided complementary information. The analysis was based on both, as the FGs and the II provided additional information. In one sense, II were deeper. However, the context of a FG discussion encouraged the participants to raise aspects that they maybe would not have reflected on, in the absence of the group dynamics. First, all the interview texts were read several times to get a sense of the whole. Next, data were divided into meaning units and then condensed and coded independently by three researchers (SS, LD, JF) The computer software Microsoft Excel, extended with sorting functions in Visual Basic for sorting functions, was used in the coding process. After comparing and preliminarily sorting the codes, two themes and four subthemes were identified (SS, LD, PS). Discussions were held between all authors throughout the analysis, involving a back and forth movement between the whole text and its parts. In this way, we tried to safe-guard the analyses. A dialogical intersubjectivity was aimed at, meaning that the authors analysed relevant interview segments separately and compared their findings. In case of any discrepancies, these were discussed, revised and validated in discussion with the other author. ${ }^{21}$ This was done by supplementing and contesting each other's readings as a part of the reflexivity process. Finally, common descriptions were formulated. An example of the data analysis is shown in table 1.

According to Graneheim et $a l^{24}$ trustworthiness in qualitative studies implies offering the most probable interpretations and can be described using three concepts: credibility, that is, how data and the analysis address the intended aim; dependability, which deals with instability and design-induced changes; and transferability, which refers to how the results could be transferred to other groups or settings. Trustworthiness was ensured by an ongoing process of reflection on these concepts.

\section{RESULTS}

In total, 36 informal caregivers, 11 women and 25 men, agreed to participate. Most of them cohabited with the patients, and were in their mid-sixties to mid-eighties, except two adult daughters and two sons, one cousin and one daughter-in-law, who were in their mid-thirties to mid-forties. The participants were all Swedish residents but had different native languages: Swedish, Finnish, Bosnian, Arabic and Turkish.

Furthermore, 17 healthcare staff from the three hospitals were interviewed about their experiences of supporting their patients' informal caregivers. They all worked with patients with COPD, and their informal caregivers, in multiprofessional teams in the pulmonary clinics. The interviewed staff had different professions such as nurses, physiotherapists, occupational therapists, physicians and counsellors. They had worked in healthcare for between 10 and 40 years (table 2).

The analysis resulted in two themes. The first theme, Ambiguity impedes provision of support, which has three subthemes, reflects the problems and challenges with caregiver support related to experiences of imprecision and uncertainty. The second theme, Knowledgeable and perceptive communication is key to support, reflects the positive experiences of dialogue and how it facilitated means to caregiver support and was a support in itself. In this way, the two themes were viewed interconnected in terms of meaning: the challenges included in the first theme are related to, and might be better managed, by the impact of facilitating communication in the second theme. Themes and subthemes are described in the text below, from both the informal caregivers' and the

\begin{tabular}{|c|c|c|c|c|}
\hline & Meaning units & Condensed meaning units & Codes & Subtheme \\
\hline Caregiver & $\begin{array}{l}\text { The society does not offer support and I don't } \\
\text { know anyone else who does. All in all, what } \\
\text { help can you get in the municipality? They } \\
\text { would probably say, "Yes, you're healthy so } \\
\text { you can do everything (in theory)," so ... so, } \\
\text { what I'm thinking is ... what kind of help can } \\
\text { a healthy person with a sick wife get? I don't } \\
\text { know that really. }\end{array}$ & $\begin{array}{l}\text { The society does not offer } \\
\text { support because I'm too } \\
\text { healthy and in theory I can do } \\
\text { everything. I don't know what } \\
\text { kind of help there is. }\end{array}$ & $\begin{array}{l}\text { Unawareness } \\
\text { Unclear } \\
\text { expectations }\end{array}$ & $\begin{array}{l}\text { Mutual } \\
\text { uncertainty }\end{array}$ \\
\hline $\begin{array}{l}\text { Healthcare } \\
\text { staff }\end{array}$ & $\begin{array}{l}\text { I don't know if it's a formal duty to support } \\
\text { the family members, but it's going to be... the } \\
\text { patient in front of you. If the relatives need } \\
\text { support, you'll talk together. }\end{array}$ & $\begin{array}{l}\text { Don't know if it's a duty to } \\
\text { support the families } \\
\text { If the relatives need support, you } \\
\text { talk. }\end{array}$ & $\begin{array}{l}\text { Don't know } \\
\text { about duty } \\
\text { Will talk if } \\
\text { needed }\end{array}$ & $\begin{array}{l}\text { Mutual } \\
\text { uncertainty }\end{array}$ \\
\hline
\end{tabular}




\begin{tabular}{|c|c|c|c|}
\hline \multicolumn{2}{|c|}{ Informal caregivers $(n=36)$} & \multicolumn{2}{|c|}{ Healthcare staff $(n=17)$} \\
\hline Age, years & $\mathrm{N}$ & Age, years & $\mathrm{N}$ \\
\hline $35-45$ & 6 & $34-45$ & 6 \\
\hline $46-65$ & 7 & $46-65$ & 11 \\
\hline $66-85$ & 23 & & \\
\hline Gender & & Gender & \\
\hline Male & 25 & Male & 2 \\
\hline Female & 11 & Female & 15 \\
\hline $\begin{array}{l}\text { Relation to the } \\
\text { patient }\end{array}$ & & Occupation & \\
\hline Spouse/partner & 30 & Nurse & 10 \\
\hline Adult child & 4 & Physician & 3 \\
\hline Other & 2 & $\begin{array}{l}\text { Allied health } \\
\text { professionals }\end{array}$ & 4 \\
\hline Employment & & $\begin{array}{l}\text { Work experience, } \\
\text { years }\end{array}$ & \\
\hline Retired & 23 & $10-40$ & 17 \\
\hline Working & 11 & & \\
\hline Unemployed & 2 & & \\
\hline
\end{tabular}

healthcare staff's perspectives (FG; II). An overview of the thematic structure is presented in figure 1 .

\section{THEME 1: AMBIGUITY IMPEDES PROVISION OF SUPPORT}

In the first theme, various ways were seen in which the informal caregivers and healthcare staff were vague and inconsistent about caregiver support. Both parts expressed a general uncertainty about whether, and what kind of, support should be provided within healthcare, and how to provide it. Indefiniteness got in the way of clear communication and mutual understanding, which increased the complex task of approaching the whole family's situation. Three subthemes related to this theme are presented below.

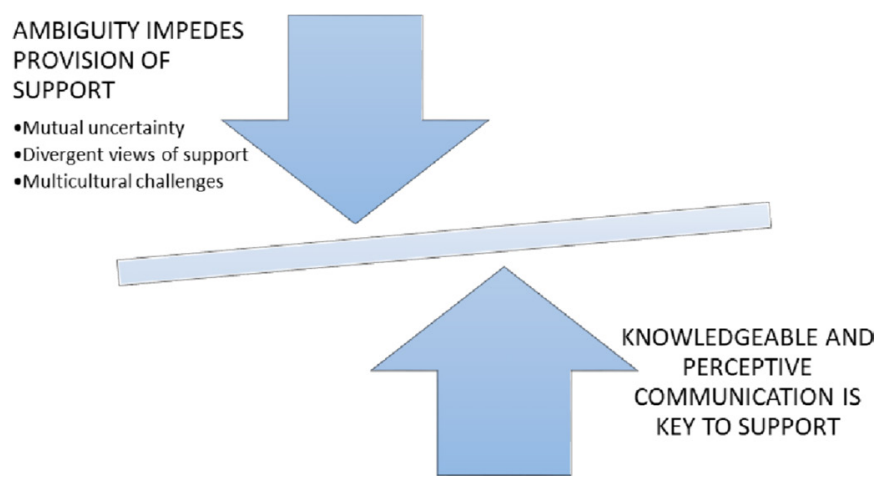

Figure 1 Themes and subthemes from the analysis of caregivers' and staff perspectives.

\section{Mutual uncertainty}

This subtheme reflects how both caregivers and healthcare staff were uncertain when it came to support from healthcare to the caregivers. The informal caregivers were vague about their needs and felt unsure about what support they could expect and ask for whereas the healthcare staff were indeterminate and imprecise about their formal role regarding caregiver support. This mutual uncertainty was interpreted to increase ambiguity in their experience of caregiver support which connects this subtheme to the theme.

\section{Informal caregivers' perspectives}

Throughout the interviews, the informal caregivers tended to start talking about their ill family member instead. They were reluctant, or not used to, talking about, their own perspective and needs in caring for their relative. They were also uncertain about what kind of support the healthcare provider could offer to them.

So, what I'm thinking is ... what kind of help can a healthy person with a sick wife get? I don't know that really. (FG, male)

Some caregivers reported suffering from stress, worry and fatigue, but still, they had neither asked for nor received support, whereas others did not present any problems at all. They were unsure about or unaware that caregivers' burden could be acknowledged and supported by healthcare. For this reason, their experiences ranged from a feeling of complete abandonment to situations with no current need of external support:

I have never been in need of any help in that way, not me anyway. (FG male, spouse)

By contrast, another participant who would have needed support and attention from healthcare, narrated the following picture:

I collapse. I take sedatives, I sleep poorly, my body aches... this burden to always take care, I can't do it anymore. So I have sought help for myself, because I can't take it anymore, not physically not mentally, I feel like I'm collapsing. (II, female spouse)

\section{Healthcare staff perspectives}

Although the healthcare staff reported that family support is important, they did not regard it an immediate or explicit part of their duties. Many were unsure of how much time and effort they were to spend on supporting the caregivers and whether it was approved by their employer. Some described a supporting role in the form of small talks or giving advice to the caregivers. When doing this, they felt that they had to make excuses for spending 'unnecessary' time on the caregivers. When providing support, practical information was perceived as the easiest part, whereas providing adequate emotional support to relatives was challenging. 
Interviewer: Do you think it's part of your duties to support close relatives to COPD patients?

Participant: No. It's not really my role because I'm here for the patient. (Physician 1)

Participant: I don't know if it's a formal duty to support the family members. (Nurse 1)

Participant: Their family are really important here; the patient will die because of their severe COPD. But the family will live on. We have to focus on them. Sometimes I get questioned about it: "You have a patient and the family are not your patients." Then I turn to the health care regulation and the law says it is our responsibility. (physician 3)

Generally, the healthcare staff focused on the patient, and not of the family members' personal needs. Even when they were directly asked about family support in the interview situation, the staff spontaneously described how the patient would benefit from taking measures to include and support the family. This perception revealed an ambiguous view, with a positive attitude to attending to the relatives, but thinking about them primarily as helpers to support the patient.

Interviewer: Do you think it's part of your duties to support close relatives to COPD patients?

Participant: Oh yes! We welcome patients to bring along their relatives, so they can get the same information. They live together! Relatives can remind the patient of what we have said. It's a good thing that there are several ears that can hear. (Allied health personnel).

However, the staff did not take for granted that the family had an open-faced relationship and that the patient wanted to share everything with their relatives. Sometimes, this made them hesitant and uncertain when the caregiver was present, since their focus was to maintain a trusting relationship with the patient.

It's great if you're on good terms with the next of kin; still, you can't go behind the back of the patient either. (Nurse 2)

\section{Divergent views of support}

This subtheme reflects the difference between the two perspectives on type of support and content: the support needed by caregivers vs the support offered by healthcare staff. Whereas informal caregivers requested emotional, practical and informational support, healthcare was mainly focusing on information-giving. This contrasting perception made a joint understanding of caregiver support difficult, thus clouding the view on how optimal support could be provided, linking to the theme.

\section{Informal caregivers' perspectives}

Many informal caregivers requested emotional support to regain control in their lives. Some of the participants also described a need for practical help with household chores, transport services, a home help caregiver who could take the ill family member to appointments, or a coordinator (eg, a contact nurse) who could interact with healthcare services to unburden the informal caregiver.

Interviewer: What kind of support would you like?

Participant: I have sought psychological help and everything like that. I feel I will break down if nobody hears me. [...] I want a relationship with my husband. I don't want to check his medications, or check clothes, no, I just want to have a good time with him. (II, female, spouse)

Participant: Hmm, my husband... he would need, like, an assistant or something. He totally lacks awareness about his own health [and his practical needs]. And I find it hard to help him with all of this. So, we need help. (II, female, spouse)

Moreover, the informal caregivers also requested more knowledge and support regarding the medical treatment. They felt insecure about their own roles; still they tried to help with the medication on a daily basis. In cases of acute exacerbation, a few caregivers even provided their relative with excessive doses of medication, randomly, in order to help.

Another kind of need that emerged was about meeting other people in similar circumstances, for example, by attending support groups in the form of COPD school - face to face or online. Not many participants had attended these meetings, but those who had, appreciated the instructive and helpful support.

\section{Healthcare staff's perspectives}

The healthcare staff mostly described family support in terms of giving information about medication, advising, answering questions about COPD or referring the informal caregiver to a counsellor or to a support group. They felt that adequate information was helpful and made the informal caregivers feel safer. The staff described that when the informal caregivers learnt more about COPD and how it can be managed, they became better at keeping their calm and therefore were more able to help the patient at home when difficulties arose.

The most obvious [action] is to help the patient and therefore we can easily forget the relatives. But we call them, answer questions, and refer them to the right authority to get help. (Nurse 4)

If a patient gets breathless at home, then it is satisfying for a close relative to know how to help. That's the kind of advice is what we give: what to do and what signs to look out for ...//...so they themselves don't get upset. Because that would only be worse for the patient. (Nurse 8)

The multiprofessional team was seen as an important tool in caregiver support. Through team efforts it was easier to discover family needs and in team discussions 
it was clarified who was best suited to give support in a certain situation.

And, of course, the team has an important role because it consists of many different professions and there is always someone who notices if a family needs extra support. (Allied health personnel)

Although staff members highlighted the idea of working in a team, teamwork was not easy to carry out in the everyday work.

\section{Multicultural challenges}

This subtheme reflects how cultural differences, explicitly and implicitly, can cause confusion and challenge a joint understanding between the informal caregivers and staff about the family's situation and support. The confusion was linked to language problems, where nuances, symbols and body language could get lost in translation, to different pre-understanding of the family system and roles of family members, and to the issue of trust.

\section{Informal caregivers' perspectives}

In some families, language barriers affected the informal caregivers, especially when no one else in the family could speak Swedish. This made them feel frustrated and overwhelmed by the full responsibility of caring for the patient.

I must always be nearby. There is no one who manages Swedish in his family but me, and it makes me responsible all the time; I'm the one who needs to take care of everything, and so on. I must often leave my job and it affects me a lot. (II female daughter-in-law)

Moreover, in some families, cultural traditions and expectations led to the perception that the everyday support for an ill family member should always be given by relatives, not by healthcare services.

Interviewer: Are there any occasions you have wished for support from health care?

Participant: No, I can handle it. If it gets difficult, my friends, cousins - my son - will help me. (II, female, spouse)

\section{The healthcare staff's perspectives}

The different languages spoken by the patients and their families were experienced as a challenge to communication. Sometimes the informal caregiver was forced to assume a role of an interpreter even if this was not desirable. Different traditions and languages challenged ordinary support arrangements. For example, ready-made food offered by the home services was not always accepted by families from non-Swedish backgrounds. Consequently, the informal caregiver was forced to perform tasks that would normally be offered by society.

They maybe need a safety alarm, and they need someone who comes to their house and, like, heats up food, or goes shopping. Those simple things. But here [in our catchment area] it can be complicated, because they don't speak Swedish, and they don't eat the food that home care services offer. And, then the relatives have to assume that role too... (Nurse 9)

Sometimes, fear of Swedish agencies and authorities became a barrier because the patients and their families were afraid to talk about their family situation. Healthcare staff needed to earn their trust to get to know about the family's situation, and then try and support them.

First, they must feel they can trust me before I get into stuff... maybe above all, when it comes to people from other cultures who have great fears of Swedish agencies, like wondering how we are linked to the Migration Board. (Physician 2)

\section{Theme 2: Knowledgeable and perceptive communication is key to support}

The second theme involves a common experience among caregivers and staff: that the quality of the personal faceto-face encounter in healthcare was a key to successful support. The staff's ability to be tactful, perceptive and inviting when communicating with the caregivers created an important, sometimes unarticulated, sense of support, when the communication worked out well. Communication meant that healthcare staff were physically and mentally present, and in this way accessible to the caregivers. Dialogue-based conversations and an empathic approach while sharing knowledge about COPD, facilitated a common understanding and enhanced trust. Thus, the communication gave possibilities to more effective and personalised caregiver support, but was also, in itself, part of the support as it calmed the caregivers and helped them reflect on strategies for their relatives and for themselves.

\section{Informal caregivers' perspectives}

Many informal caregivers felt a need and desire to talk to the doctor or nurse during medical appointments. To have someone to talk to helped, or would help, them to better deal with the stressful situation and their own feelings of vulnerability or exhaustion. When lacking someone to talk to, the caregivers felt frustrated or anxious.

I know they can't get her illness to disappear, but still it's important to know whom to turn to when she gets ill. I usually call the nurses, it feels good and safe. (II, male, spouse)

She suffers from a serious illness [COPD] and it actually gives me a lot of anxiety. It would be helpful to have someone to talk to. Just to be able to talk to someone. There hasn't been that opportunity. (II, male spouse)

The informal caregivers needed to be seen, listened to and taken seriously and they felt supported when staff attended to them with openness and empathy. This 
feeling was not primarily about what the staff said, but, rather, about having their own feelings recognised.

Healthcare professionals do not talk very much to me, but [still] they are there. It's pretty safe. No, I haven't been forgotten. (FG, male spouse)

The informal caregivers also wanted the healthcare staff to take their inside knowledge seriously. After many years of experience, they had developed an awareness, for example, for observing early signs of impending exacerbation, and they knew when it was time to contact healthcare services or go to the emergency department. They learnt to trust in their own ability. However, some felt that healthcare staff ignored their observations when they came to the emergency department, which led to feelings of frustration.

I trust what I see. With time, I've gotten pretty good at seeing when it's time to go to the hospital. (II female, spouse)

\section{Healthcare staff's perspectives}

While most of the staff focused on how family caregivers would be able to support the patient, some recognised the caregivers' personal needs. They described that although giving advice or information was the main formal caregiver support, they described a need to see the caregivers and recognising their individual needs. It was important to be tactful and sensitive to the caregiver's need for support, in the context of their life situation. The staff reported that careful and perceptive listening led to increased ability to build a trustful relationship with the caregiver, which sometimes succeeded and sometimes was very difficult. The dialogue was seen as valuable for two reasons; it provided immediate emotional support and it was a way to explore where to refer the informal caregiver for further support, for example, to another member in the team or to psychosocial services.

Interviewer: What does it mean to you to support close relatives?

Participant: It means to affirm their feelings, their worries, and concerns. In some way, to meet them, where they are... let questions come forward. The spouses are so focused on the patient that they don't always consider their own needs. Then you can actively say, "It's a tough situation and you may need support." (Physician 3)

\section{DISCUSSION}

Our main finding was that both informal caregivers and healthcare professionals felt uncertain about expectations on caregiver support and whether it was an alleged duty. And if so, there was no clear guidelines or consensus about when support should be offered and in what form. Still, the needs were obvious. The caregivers did not want to be regarded as mere patient care facilitators but described a need to be supported and to be seen themselves. Furthermore, they requested more information, in order to cope with the situation. Information-seeking is a powerful coping strategy and, similarly to caregivers of other patient groups, the caregivers in our study wanted more knowledge ${ }^{25}{ }^{26}$ However, they also sought emotional support for themselves, although their focus was on their sick relative.

These findings can be discussed in relation to the theoretical framework about caregivers in palliative care, proposed by Andershed and Ternestedt. ${ }^{27}$ The authors describe a model the caregiver's experience using two theoretical blocks. One was related to the caregiver's concrete involvement such as information and tasks: 'to know', 'to be' and 'to do' and the second one was conceptualised as 'involvement in the dark' versus 'involvement in the light'. The metaphor of 'involvement in the dark' can be related to our first theme which brings up perceptions of uncertainty, confusion, unawareness and ambiguity. In line with our results emphasising communication, the model by Andershed and Ternested ${ }^{27}$ described that factors promoting caregivers' 'involvement in the light', are good relationships with healthcare staff, professional care based on humanistic values, a sense of coherence and appropriate illness trajectory.

The informal caregivers also had other needs, some of which were beyond the normal scope of healthcare. They requested support in household tasks or help with making appropriate contacts for other forms of support which all are relevant aspects. Inspired by transition care processes, proposed in previous research, ${ }^{28}$ support by team coordinators, could be a way to address the gap between the information-based support offered and the practical support requested to unburden daily life. Although the healthcare team cannot provide all aspects of support, a coordinator with broad knowledge of COPD in different societal contexts-for example, home care, benefits and housing assistance-may help direct caregivers of useful local resources.

Many of the caregivers in this and our previous study ${ }^{7}$ felt tied to their homes, in agreement with other studies, ${ }^{29}$ and it is known that informal caregivers are at risk of social isolation and illness. Even when staff recognised the problem, some staff still stated that they lacked the time to support the caregivers and that providing caregiver support was not a formal duty. However, most of them tried to do it anyway.

This staff underlined the benefits of teamwork; still, the informal caregivers were not sure about how the multiprofessional approach was explicitly helpful to them. Obviously, having access to different professionals is not equal to actual teamwork. Teamwork is an independent model of working. Increased knowledge and awareness about how a team should work, may improve communication and the team's opportunity to address complex needs. $^{30}$

Our data also indicate that the informal caregivers felt ignored, if their in-depth experience of living with their 
sick relative was not acknowledged, in line with previous research. ${ }^{31}$ In certain aspects, informal caregivers want to be a part of the team helping the patient, and as a family member, one has unique insight into the daily living of the patient. Experienced and well-informed caregivers may, in fact, be the first to notice exacerbation. In this way, informal caregivers can facilitate timely medical decisions. This suggests a need for professionals to listen, open-mindedly and with attention, to tacit needs and cues.

To support family caregivers is a delicate task, as some informal caregivers do not want to focus on themselves. However, they might be more willing to explore their own needs when the professional explains why caregiver support is important. If the professionals are perceptive, they will know not to offer extended support to those who feel capable on their own, and in that way more resources can be allocated to those with greater needs. This is of utmost importance also in a multicultural society, where perception of healthcare differs depending on cultural background and values, and differences may generate significant stress, both physically and mentally. ${ }^{32}$

Supporting the families and working in team have always been natural parts in palliative care. This is obvious especially in cancer care, where the families participate in the planning of care and receive adequate support from the healthcare team if needed. ${ }^{1433}{ }^{34}$ However, this is less self-evident for the informal caregivers to patients with severe COPD, although they would benefit from being included in a holistic palliative care, due to the severity of the disease. ${ }^{18}$

The importance of including families is highlighted in family-focused care, where a therapeutic conversation is essential. Although there are not many implementation studies in COPD settings, Halldórsdóttir and Svavarsdóttir found that families who were offered the therapeutic conversations intervention, felt more supported, both on a cognitive and emotional level. ${ }^{14}$ The therapeutic conversation interventions have proved to be beneficial and supportive to the caregivers in other caregiver populations such as adolescents with Attention deficit hyperactivity disorder (ADHD) and caregivers of people with eating disorders. Thus, the therapeutic conversations between healthcare staff and families experiencing illness, may offer and enable potential for family-healing. ${ }^{35} 36$

To enhance caregiver support, the skills about how to support and talk to families and the well-being of the whole family-both the patient and their relatives-we suggest that a family focused care should guide future developments in COPD healthcare in order to alleviate the heavy burden of the informal caregiver.

We also suggest raising awareness and clarifying the obstacles to caregiver support, mainly illustrated by the first theme in our results, but also by the described possibilities such as the effects of sensitive communication. This could be a first step towards developing effective strategies to assist the caregivers. ${ }^{37}$ If informal caregivers feel supported, they can also be made more confident to act as 'health care advocates'. In this way, their sick relatives' self-management is likely to improve, reducing the risk of frequent hospital readmissions.

\section{Strengths and limitations}

The sampling strategy with a large and varied sample, enabled saturation and allowed a comparison of both caregivers' and professionals' experiences which were considered strengths. Another strength was the multidisciplinary research team providing different perspectives to the analysis.

The main limitation of the study is that the results are context-specific and might therefore not be transferable to other countries, or other healthcare systems. We encourage more studies, preferably in other multicultural societies, to see if results share common themes and discuss divergences.

Another limitation was that, surprisingly, the majority of the caregivers participating in our study were men. Although the reason for the male over-representation remains unknown, be that the study was performed in an ethnically diverse area, with many families coming from more patriarchal societies where men are more prone to represent the family outside the household. In our study, the women had difficulties leaving their sick husbands alone in order to participate in the interview. Considering gender distribution in the sample would be desirable in future studies on caregivers in multicultural societies.

\section{CONCLUSIONS}

In this study, despite obvious needs, both informal caregivers and healthcare staff experienced vagueness and lack of clarity related to caregiver support regarding variations in needs, expectations, duties and what the support should entail. We found that support, based on knowledgeable and tactful communication in the healthcare encounter, is essential. While keeping emphasis on sensitive communication, increasing clarity about roles and needs-at the organisational, team and individual levelcould enhance caregiver support from healthcare. In this way, COPD caregiver support could develop towards a family perspective that is advocated in family nursing and in palliative care.

Acknowledgements We would like to thank all informants for participating in the interviews and our nursing students, for carrying out the interviews.

Contributors The project was designed and developed by SS and PS. Data were collected by JF, SS and AR. SS, JF, LD and PS performed data analysis. SS, PS and LD contributed to the drafting and revising of the manuscript. All authors approved the final version of the manuscript for publication.

Funding The authors have not declared a specific grant for this research from any funding agency in the public, commercial or not-for-profit sectors.

Competing interests None declared.

Patient consent for publication Not required.

Ethics approval Ethical approval was obtained from the Regional Ethics Committee in Gothenburg, Sweden (Dnr: 645-16).

Provenance and peer review Not commissioned; externally peer reviewed. 
Data availability statement Data are available upon reasonable request.

Open access This is an open access article distributed in accordance with the Creative Commons Attribution Non Commercial (CC BY-NC 4.0) license, which permits others to distribute, remix, adapt, build upon this work non-commercially, and license their derivative works on different terms, provided the original work is properly cited, appropriate credit is given, any changes made indicated, and the use is non-commercial. See: http://creativecommons.org/licenses/by-nc/4.0/.

\section{REFERENCES}

1. Strang S, Ekberg-Jansson A, Strang P, et al. Palliative care in COPD - web survey in Sweden highlights the current situation for a vulnerable group of patients. Ups J Med Sci 2013;118:181-6.

2. Vogelmeier CF, Criner GJ, Martinez FJ, et al. Global strategy for the diagnosis, management and prevention of chronic obstructive lung disease 2017 report. Respirology 2017;22:575-601.

3. Ek K, Andershed B, Sahlberg-Blom E, et al. "The unpredictable death" - The last year of life for patients with advanced COPD: Relatives' stories. Pall Supp Care 2015;13:1213-22.

4. Mi E, Mi E, Ewing G, et al. Associations between the psychological health of patients and carers in advanced COPD. Int $J$ Chron Obstruct Pulmon Dis 2017;12:2813-21.

5. Mathews G, Johnston B. Palliative and end-of-life care for adults with advanced chronic obstructive pulmonary disease: a rapid review focusing on patient and family caregiver perspectives. Curr Opin Support Palliat Care 2017;11:315-27.

6. Figueiredo D, Gabriel R, Jácome C, et al. Caring for relatives with chronic obstructive pulmonary disease: how does the disease severity impact on family carers? Aging Ment Health 2014;18:385-93.

7. Strang S, Osmanovic M, Hallberg C. Family caregivers' heavy and overloaded burden in advanced COPD. Journal of Palliative Medicine 2018;21.

8. Simpson AC, Young J, Donahue M, et al. A day at a time: caregiving on the edge in advanced COPD. Int $J$ Chron Obstruct Pulmon Dis 2010;5:141-51.

9. Baanders AN, Heijmans MJ. The impact of chronic diseases: the partner's perspective. Fam Community Health 2007;30:305-17.

10. Kimbell B, Boyd K, Kendall M, et al. Managing uncertainty in advanced liver disease: a qualitative, multiperspective, serial interview study: Table 1. BMJ Open 2015;5): :e009241.

11. Mcllfatrick S, Doherty LC, Murphy M, et al. 'The importance of planning for the future': Burden and unmet needs of caregivers' in advanced heart failure: A mixed methods study. Palliat Med 2018;32): :881-90.

12. Who definition of palliative care. Available: ehttp://www.who.int/ cancer/palliative/definition/en/

13. National Board of Health and Welfare. Stöd till personer SOM vårdar och stödjer närstående. Available: http://www.socialstyrelsen.se/ Lists/Artikelkatalog/Attachments/19605/2014-12-6.pdf

14. Halldórsdóttir BS, Svavarsdóttir EK. Purposeful therapeutic conversations: are they effective for families of individuals with COPD: a quasi-experimental study. Nordic Journal of Nursing Research 2012;32:48-51.

15. Farquhar M. Assessing carer needs in chronic obstructive pulmonary disease. Chron Respir Dis 2018;15:26-35.

16. Bove DG, Zakrisson A-B, Midtgaard J, et al. Undefined and unpredictable responsibility: a focus group study of the experiences of informal caregiver spouses of patients with severe COPD. J Clin Nurs 2016;25:483-93.

17. Graneheim UH, Lundman B. Qualitative content analysis in nursing research: concepts, procedures and measures to achieve trustworthiness. Nurse Educ Today 2004;24:105-12.

18. O'Brien BCet al. Standards for reporting qualitative research: a synthesis of recommendations. Acad Med 2014;89): :1245-51.

19. Kitzinger J. Qualitative research: introducing focus groups. BMJ 1995;311:299-302.

20. Patton MQ. Qualitative evaluation and research methods. Newbury Park: Saga Publications, 1990.

21. Kvale S, Brinkmann S. InterViews. In: Learning the craft of qualitative research interviewing. 2nd edn. Thousand Oaks, CA: Sage Publications, Inc, 2009.

22. Saunders B, Sim J, Kingstone T, et al. Saturation in qualitative research: exploring its conceptualization and operationalization. Qual Quant 2018;52:1893-907.

23. Krippendorff K. Content analysis: An introduction to its methodology. 18. Sage, 2004.

24. Graneheim UH, Lindgren B-M, Lundman B. Methodological challenges in qualitative content analysis: a discussion paper. Nurse Educ Today 2017;56:29-34.

25. Mcllfatrick S, Doherty LC, Murphy M, et al. 'The importance of planning for the future': Burden and unmet needs of caregivers' in advanced heart failure: A mixed methods study. Palliat Med 2018;32:881-90.

26. Miller LE. Uncertainty management and information seeking in cancer survivorship. Health Commun 2014;29:233-43.

27. Andershed B, Ternestedt BM. Being a close relative of a dying person. Development of the concepts "involvement in the light and in the dark". Cancer Nurs 2000;23): :151-9.

28. Kripalani S, Theobald CN, Anctil B, et al. Reducing Hospital readmission rates: current strategies and future directions. Annu Rev Med 2014;65:471-85.

29. Nakken N, Janssen DJA, van den Bogaart EHA, et al. Informal caregivers of patients with COPD: home sweet home? Eur Respir Rev 2015;24:498-504.

30. Hussain FA, Williams S. Copd: a proposed multidisciplinary approach to psychological issues. British Journal of Nursing 2017;26:1109-15.

31. Aasbø G, Rugkåsa J, Solbraekke KN, et al. Negotiating the caregiving role: family members' experience during critical exacerbation of COPD in Norway. Health Soc Care Community 2017;25:612-20.

32. Brooke J, Cronin C, Stiell M, et al. The intersection of culture in the provision of dementia care: a systematic review. J Clin Nurs 2018;27:3241-53.

33. Arestedt L, Benzein E, Persson C. Families living with chronic illness: beliefs about illness, family, and health care. J Fam Nurs 2015;21:206-31.

34. Sun V, Grant M, Koczywas M, et al. Effectiveness of an interdisciplinary palliative care intervention for family caregivers in lung cancer. Cancer 2015;121:3737-45.

35. Wright LM. Brain science and illness beliefs: an unexpected explanation of the healing power of therapeutic conversations and the family interventions that matter. J Fam Nurs 2015;21:186-205.

36. Gisladottir M, Svavarsdottir EK. The effectiveness of therapeutic conversation intervention for caregivers of adolescents with ADHD: a quasi-experimental design. J Psychiatr Ment Health Nurs 2017;24:15-27.

37. Bryant J, Mansfield E, Boyes A, et al. Involvement of informal caregivers in supporting patients with COPD: a review of intervention studies. Int J Chron Obstruct Pulmon Dis 2016;11:1587-96. 